\title{
One-Step Synthesis of Versatile Antimicrobial Nano-Architected Implant Coatings for Hard and Soft Tissue Healing
}

\author{
Martin T. Matter, Leonida Maliqi, Kerda Keevend, Stefanie Guimond, Judith Ng, Efe Armagan, \\ Markus Rottmar, and Inge K. Herrmann*
}

Cite This: ACS Appl. Mater. Interfaces 2021, 13, 33300-33310

Read Online

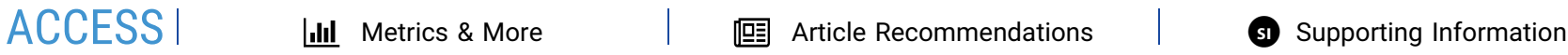

ABSTRACT: Dental implant failure remains a prevalent problem around the globe. The integration of implants at the interface of soft and hard tissues is complex and susceptible to instability and infections. Modifications to the surface of titanium implants have been developed to improve the performance, yet insufficient integration and biofilm formation remain major problems. Introducing nanostructures on the surface to augment the implant-tissue contact holds promise for facilitated implant integration; however, current coating processes are limited in their versatility or costs. We present a highly modular singlestep approach to produce multicomponent porous bioactive nanostructured coatings on implants. Inorganic nanoparticle building blocks with complex compositions and architectures are synthesized in situ and deposited on the implants in a single step using scalable liquid-feed

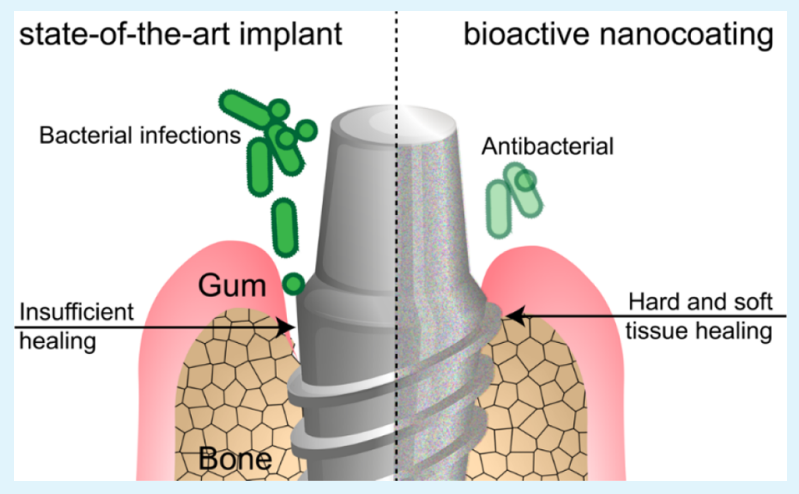
flame spray pyrolysis. We present hybrid coatings based on ceria and bioglass, which render the implant surfaces superhydrophilic, promote cell adhesion, and exhibit antimicrobial properties. By modifications to the bioglass/ceria nanohybrid composition and architecture that prevent biomineralization, the coating can instead be tailored toward soft tissue healing. The one-step synthesis of nano-architected tissue-specific coatings has great potential in dental implantology and beyond.

KEYWORDS: antimicrobial, bioactive, flame spray pyrolysis, porous, scalable

\section{INTRODUCTION}

Titanium has been used for dental implants since the 1960s and has shown the ability to promote bone integration. ${ }^{1}$ Despite the current trend toward metal-free alternatives, it is still the most widely used dental implant material. ${ }^{2}$ However, titanium implants suffer from several shortcomings, including insufficient soft tissue integration and vulnerability to biofilm formation. Additionally, recent reports have raised concerns about Ti toxicity ${ }^{3}$ and allergies. ${ }^{4}$ Ceramic-based alternatives are promising; however, processing and shaping them is demanding, and thus accessible design options are limited, which render complex tooth restoration challenging.

Lately, researchers have aimed to improve $\mathrm{Ti}$ implant surfaces with a variety of techniques to promote healing. ${ }^{2}$ One commonly used method that has shown clinical benefits is the introduction of nanostructures to the surface. ${ }^{5,6}$ The advent of nanotechnology has given rise to a plethora of new materials where interactions can be controlled on the nanoscopic scale. In particular, the importance of nanomaterials in medicine and their potential to propel healthcare to a new era have been recognized. ${ }^{7}$ While many nanodrugs, such as liposomal carriers and imaging agents, have experienced extensive regulatory scrutiny, ${ }^{8}$ nanostructured implants have found increasingly facilitated application in clinics due to alleviated toxicity concerns. ${ }^{9}$ Nanostructured surfaces have found particular favor within the dental implant field, which deals with complex insertion procedures and the intricate soft-hard tissue interface; hence, an in-depth and versatile control of the implant-tissue interface is pivotal. ${ }^{10}$

Nanostructured implants have an increased surface area, allowing for increased adsorption of proteins and improved attachment of cells to the implant. ${ }^{10,11}$ While there are various techniques $^{12}$ used to modify $\mathrm{Ti}$ surfaces to introduce nanoroughness, such as etching or laser pitting, ${ }^{12,13}$ coating the implant with nanostructured inorganic materials has proven to be versatile and effective. ${ }^{4}$ This bottom-up approach allows for the precise control of surface characteristics and the introduction of biologically active components onto the implant surface. Prime components include

Received: May 31, 2021

Accepted: June 16, 2021

Published: July 13, 2021 
Scheme 1. Conventional LF-FSP for the Production of Nanoparticles (or Nanohybrids) that Can Be Collected on a Filter Mounted above the Flame (Left); Minor Modifications to the Setup Allow Direct Coating of Implant Surfaces with Nanoparticle Building Blocks Using the Same Liquid Precursors (Right)

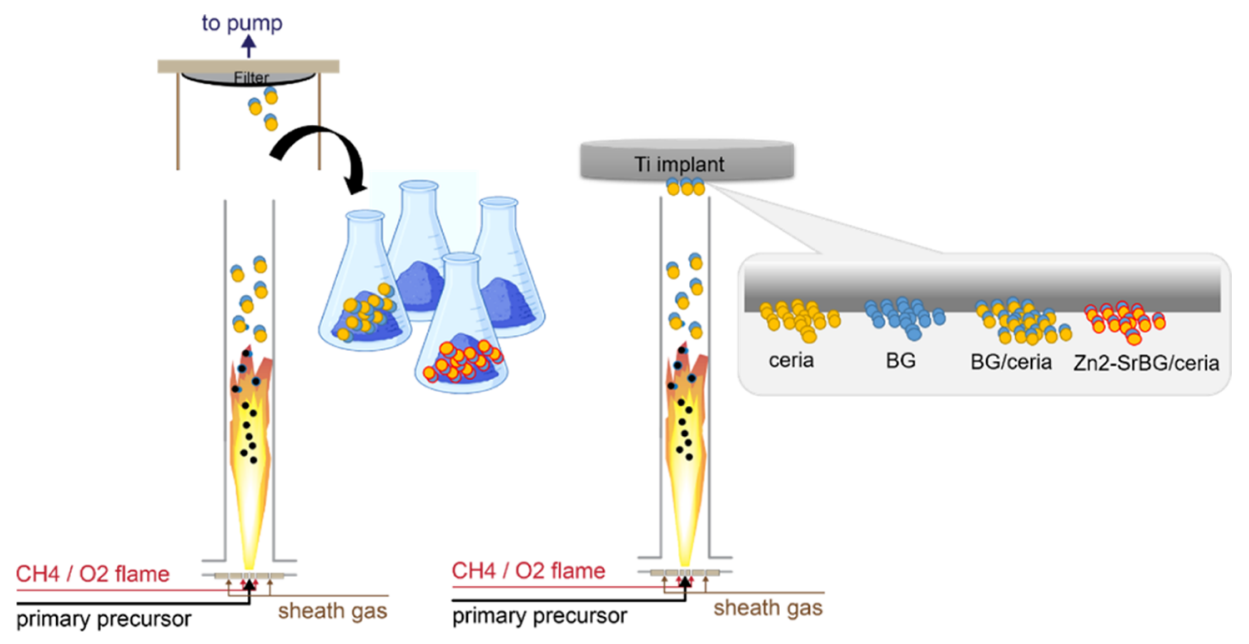

osteoconductive materials such as calcium phosphate nanocrystals or anti-infectives such as silver nanoparticles. ${ }^{13}$ Besides roughness and porosity, wettability plays an important role in wound healing kinetics: increased hydrophilicity of surfaces leads to faster protein adsorption, fibrin network formation, and cell adhesion, ${ }^{15}$ all of which lead to improved tissue integration. ${ }^{16-18}$ To improve the implant surface porosity, roughness, and wettability and to incorporate bioactive components, a wide spectrum of nanocoating techniques has been utilized on dental implants. The most frequently used techniques are reviewed by Rodriguez y Baena et al. ${ }^{19}$ and include plasma spraying, sol-gel processing, and sputtering. ${ }^{12}$ These techniques are readily used to coat $\mathrm{Ti}$ surfaces with bioactive metal oxide nanoparticles such as $\mathrm{Al}_{2} \mathrm{O}_{3}, \mathrm{ZnO}$, or hydroxyapatite (HA). ${ }^{14}$ Moreover, magnetron sputtering has been employed to control the valence state of nanoceria coatings, and with it, its immunomodulating and osteogenic properties. ${ }^{20}$ However, magnetron sputtering suffers from low deposition rates and high cost. ${ }^{21}$ In general, the control over the nanoparticle architecture, and hence the ability to steer the biological response, is limited in currently available coating processes or requires complex, multistep synthesis procedures. Recently, Nasiri et al. ${ }^{22}$ employed liquid-feed flame spray pyrolysis (LF-FSP) to deposit highly porous HA nanocoatings on Ti disks in one step. While the deposition of HA by LF-FSP resulted in the promotion of osteoblast infiltration, and potentially osteoinduction, HA implant coatings suffer from instability $^{23}$ and are limited to their beneficial properties related to osseointegration. However, especially in a dental implant context, poor soft tissue integration is recognized as the primary cause of implant-associated infections and a major contributor to implant failure. ${ }^{24}$ This is why antibacterial properties, soft tissue adhesion, and the resulting integration into the gum are just as important for implant coatings. In contrast to the aforementioned methods, coating by LF-FSP is scalable and offers a great degree of freedom and control in terms of nanostructure size, composition, architecture, and physicochemical characteristics (including valence states), 25,26 translating to catalytic (bio)activity ${ }^{27}$ which has yet to be harnessed for the creation of bioactive coatings. In LF-FSP, nanohybrid building blocks can be synthesized in situ and directly deposited on implant surfaces in a single-step process.
Recently, LF-FSP-synthesized nanoparticle hybrid suspensions have been developed to unify the adhesive and tissue regenerative activities of bioglass (BG) and ceria for the promotion of wound healing. ${ }^{2-30}$ In this work, we develop nanostructured implant coatings based on such multi-metal oxide nanohybrid building blocks tailored to both hard and soft tissue healing. A modified LF-FSP setup (Scheme 1) is employed to directly coat $\mathrm{Ti}$ implant surfaces with multicomponent nanoparticle hybrids based on cerium oxide (ceria) and BG. Ceria has proven anti-inflammatory and antimicrobial properties in its nanoparticulate form. ${ }^{27,31,32} \mathrm{BG}$ is an amorphous, bioactive glass (consisting of $\mathrm{SiO}_{2}, \mathrm{CaO}, \mathrm{Na}_{2} \mathrm{O}$, and $\mathrm{P}_{2} \mathrm{O}_{5}$ ) and has been used as a coating, especially for HA mineralization, which promotes osseointegration. ${ }^{31,32}$ As Brunello et al. ${ }^{23}$ stated, BG coatings could overcome many of the drawbacks of $\mathrm{HA}$, including chemical instability and delamination.

To further tailor the properties of BG/ceria to soft tissue healing, the nanoparticle composition was adjusted to accommodate strontium oxide in the BG matrix and was doped with $2 \% \mathrm{Zn}$ ( $\mathrm{Zn} 2-\mathrm{SrBG} /$ ceria). Strontium has been chosen for its beneficial effects on endothelial cell proliferation and tubule formation (linked to angiogenesis) as well as osseointegration. ${ }^{33,34}$ Zinc has, in addition to its angiogenic effects, ${ }^{35}$ antimicrobial properties, ${ }^{36}$ which can prevent biofilm formation on the implant. Following physicochemical, topography, and stability evaluation of the implant surfaces, the early steps of implantation are simulated by treatment with blood. Subsequent seeding of osteoblasts shows excellent cell attachment. The stimulation of endothelial cells and human fibroblasts by the nanocoating building blocks suggests good soft tissue indication of the novel nanocoatings. Furthermore, the antimicrobial potential of the implant coatings against antibiotic-resistant bacteria is demonstrated. Taken together, we present nano-architected coatings based on BG, ceria, and their combination produced in a scalable and single-step LFFSP-based process, featuring bioactivities tailored to soft and hard tissue healing.

\section{RESULTS AND DISCUSSION}

Using LF-FSP, different nanocoatings were produced by in situ coating Ti disks with either pure BG, pure ceria, or BG/ceria 

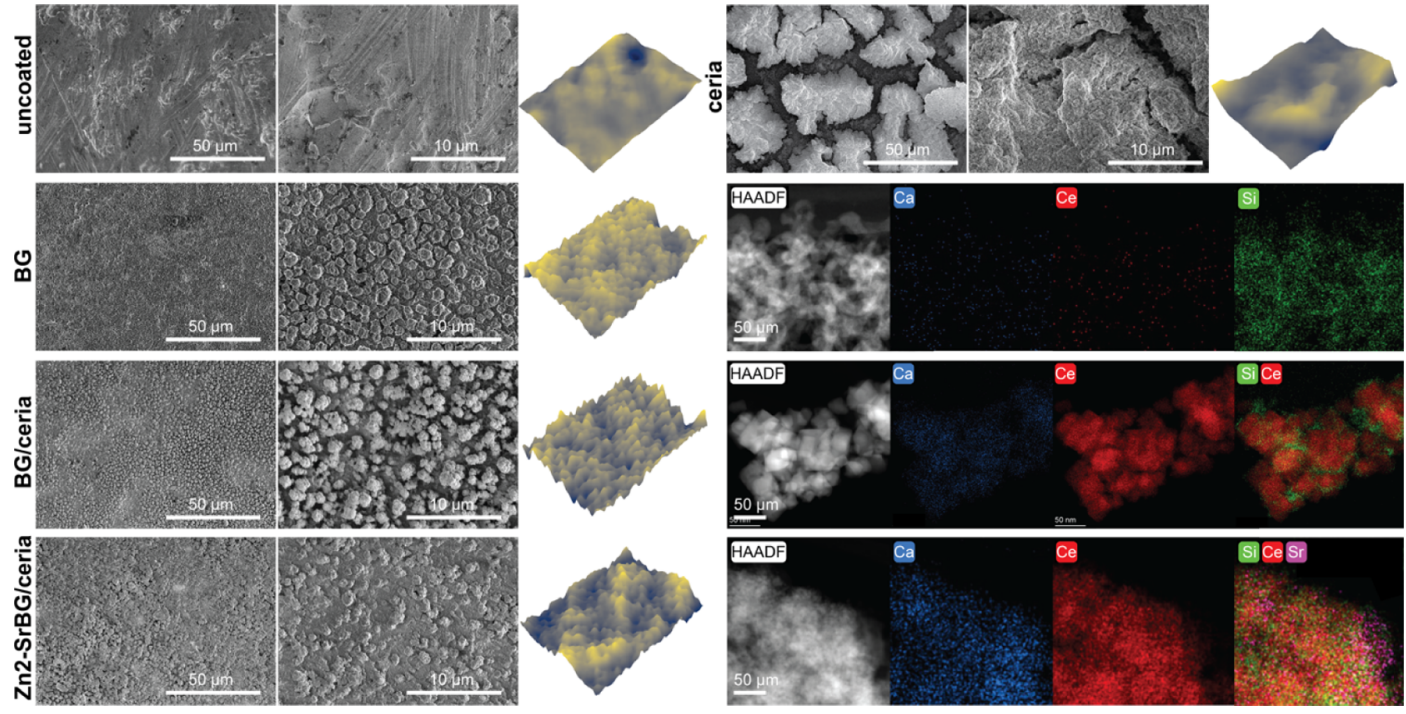

Figure 1. Topographic characterization of the coated and uncoated disks by SEM (see Figure S2 for EDX point spectra) and the corresponding 3D reconstructions of the SEM micrographs. Scanning transmission electron microscopy (STEM) micrographs and EDX elemental mappings of nanoparticles that were mechanically scraped off the disks.

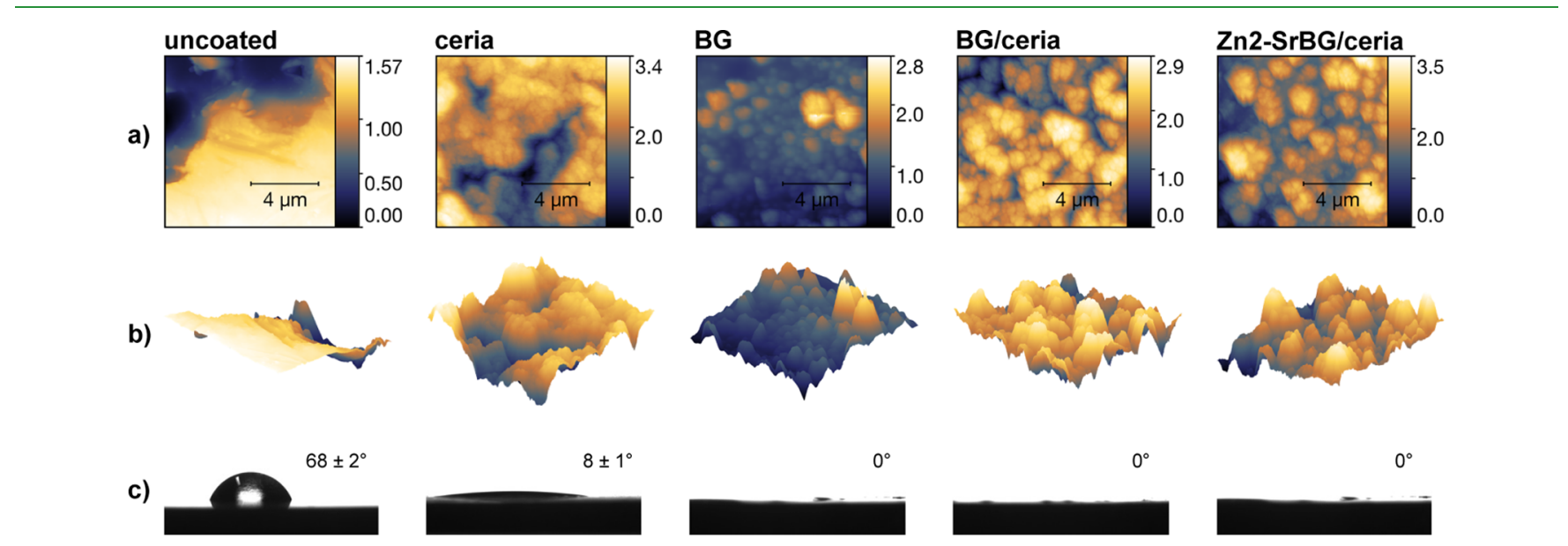

Figure 2. (a) Topography of the implant surfaces assessed by AFM (values in $\mu \mathrm{m}$ ). (b) 3D renderings of the measured area. (c) Water contact angle measurements on the uncoated and coated surfaces.

hybrid nanoparticles. The nanoparticle size, composition, and valence states can be readily varied by changing the process parameters, such as the precursor-to-dispersion ratio or the feed rate (as is thoroughly discussed for ceria in Figure S1). The ability to control the properties of nanoparticles, which make up the functional building blocks of the coating, is of utmost importance in tailoring the biological response.

The surface characteristics of the implant govern the body's initial response upon anchoring and thus play a major role in implant healing. Protein adsorption, fibrin formation, and cell adhesion are driven by surface topography and wettability. These processes not only affect the extracellular environment but also the intracellular signaling via mechanotransduction. $^{37,38}$ Scanning electron microscopy (SEM, Figure 1) of the noncoated and the coated $\mathrm{Ti}$ surfaces illustrates the different topographies achieved by the flame spray coating. The ceria coatings are comparatively nonuniform and exhibit cracks between large particle aggregates. On the other hand, the BG coatings are more uniform, with a regular distribution of cauliflower-like particle aggregates with diameters of 500$1000 \mathrm{~nm}$. The BG/ceria hybrid coatings consist of particle aggregates similarly sized to the ones observed for the BG coatings, albeit the latter are less uniform and contain more defects. The Sr matrix-substituted hybrid coatings (Zn2-SrBG/ ceria) are more uniform, and particle aggregates were found to be around $300 \mathrm{~nm}$. Additionally, all BG-containing coatings are highly porous and show a large number of protrusions. Energydispersive X-ray spectroscopy (EDXS) and elemental analysis by inductively coupled plasma spectroscopy confirm the elemental composition of the different nanoparticle coatings (see Figures 1 and S2).

While the $\mathrm{BG} /$ ceria coating contains segregated rhombohedral ceria crystals surrounded by BG entities, the Zn2-SrBG/ ceria coating shows a relatively uniform distribution of elements, hinting at more intermixed BG and ceria phases. The partial substitution of $\mathrm{Ca}$ with $\mathrm{Sr}$ in the $\mathrm{Zn} 2-\mathrm{SrBG} /$ ceria coatings is detectable by EDXS. The $\mathrm{Zn}$ content, however, is too low to yield an EDX signal but was confirmed by inductively coupled plasma optical emission spectrometry. Atomic force microscopy (AFM) measurements (Figure 2) are in line with the SEM data: the ceria coatings exhibit cracks and coarse textures, as opposed to the BG-containing coatings. The 

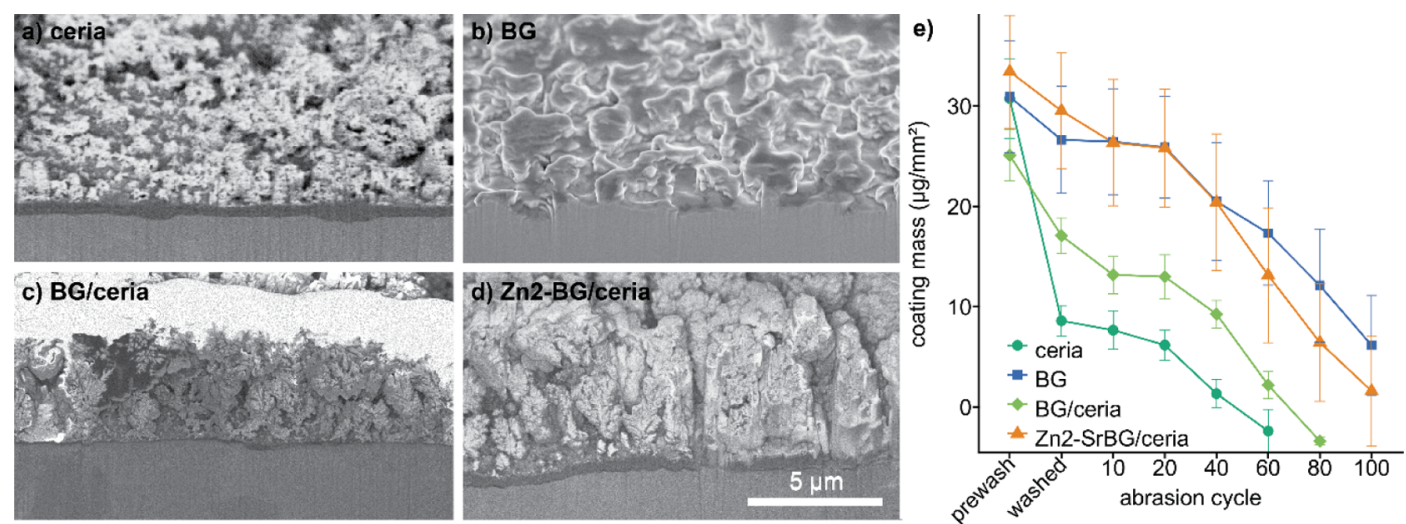

Figure 3. SEM of FIB cross sections of coated Ti implants: (a) ceria, (b) BG, (c) BG/ceria, and (d) Zn2-BG/ceria. (e) Abrasion measurements according to the ASTM F1978 abrasion resistance norm for implant coatings $(n=3$, mean \pm SE shown).
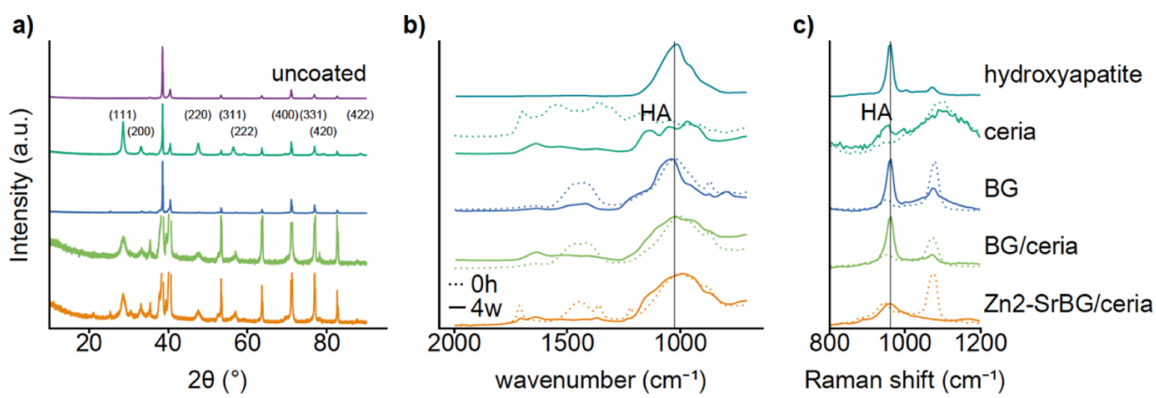

Figure 4. (a) XRD patterns of the coated disks. The main ceria diffraction peaks are indicated in parentheses. ${ }^{53}$ All other peaks stem from the Ti substrate. The ceria-containing samples were normalized to the ceria (111) peak. (b) FTIR and (c) Raman spectroscopy data confirm the formation of HA ("HA" indicates the main hydroxyapatite peak) phase after the immersion of BG and BG/ceria in simulated body fluid (SBF) for 4 weeks. In contrast, $\mathrm{Zn2}-\mathrm{SrBG} /$ ceria implant surfaces do not biomineralize. Dashed lines indicate the spectra of the samples prior to incubation in SBF.

latter all show cauliflower-like particle aggregate sizes of 300$1000 \mathrm{~nm}$

Micro- and nanoroughness have different impacts on the adhesion of biological components and thus implant healing. ${ }^{39}$ Nanoroughness has been shown to promote protein adsorption, attachment of osteoblast cells, and incorporation of growth factors into the coatings. The majority of commercial dental implants exhibit surface roughnesses around $0.5-2 \mu \mathrm{m} .{ }^{10,40}$ The nanoroughness of the nanocoatings was quantified by AFM (lateral resolution of $10 \mathrm{~nm}$ and scan of $100 \mu \mathrm{m}^{2}$ ), while 3D optical profilometry (lateral resolution of $1.4 \mu \mathrm{m}$ and scan of $2.4 \mathrm{~mm}^{2}$ ) was used to measure the microroughness. The coatings greatly increased both the micro- and nanoroughness of the surface, yielding average roughness values between 0.2 and $0.8 \mu \mathrm{m}$ (Table S1), offering cells a larger surface area to attach in comparison to uncoated surfaces. The wettability of the implant surfaces plays a pivotal role in the initial blood and cell contact. ${ }^{41}$ While most commercial implant surfaces are only moderately hydrophilic (water contact angle, WCA $\left.>50^{\circ}\right),{ }^{10}$ recent trends in implantology move toward superhydrophilic surfaces as they have been shown to facilitate cellular adhesion and tissue healing. ${ }^{41}$ The hydrophilicity of the produced coatings was assessed by WCA measurements, and while the bare Ti surface is only slightly hydrophilic with a WCA of $68^{\circ}$, coating the Ti surface with ceria renders it more hydrophilic, yielding a WCA of $8^{\circ}$. Notably, all BG-containing coatings are superhydrophilic with WCAs of $0^{\circ}$, making them promising candidates for enhanced tissue attachment. ${ }^{41,42}$
To determine the thickness and inner morphology of the coatings, focused ion beam SEM (FIB-SEM) was performed (Figure 3). A focused gallium ion beam was used to cut a trench $^{43}$ into the implant surface, and the polished cross section was subsequently imaged by SEM. Figure 3 shows an $\sim 5 \mu \mathrm{m}$ thick layer of nanoparticles for all ceria-containing coatings. Thicknesses for pure BG coatings are slightly reduced to $\sim 2-3 \mu \mathrm{m}$ for the same deposition times. While the ceria coatings feature a highly porous network of small structures, the BG coatings appear more sintered with larger features. These larger structures are in line with the topography observed in Figure 1. The two hybrid coatings feature the elements of the network structures of small nanoparticles surrounded by larger structures that appear more compact. All coatings, particularly the ceria-containing ones, are highly porous with a branching nanoparticle network. The porosity was calculated based on the thickness estimated from the FIBSEM cross sections and the material mass density, assuming homogeneous coverage and thickness over the entire surface. The porosity percentages around $90 \%$ shown in Table S2 are considerably higher than those obtained by alternative coating techniques ${ }^{4-46}$ and are in good agreement with the values previously reported for LF-FSP HA coatings. ${ }^{22}$ Porous coatings have proven to be beneficial for cell adhesion and interaction, supposedly due to the increased contact area. ${ }^{10}$ Note also that the nanoparticle coating stability on the titanium surface is critically dependent on various parameters, including the nanoparticle material; delamination and partial detachment from the surface are observed in the case of pure ceria. 

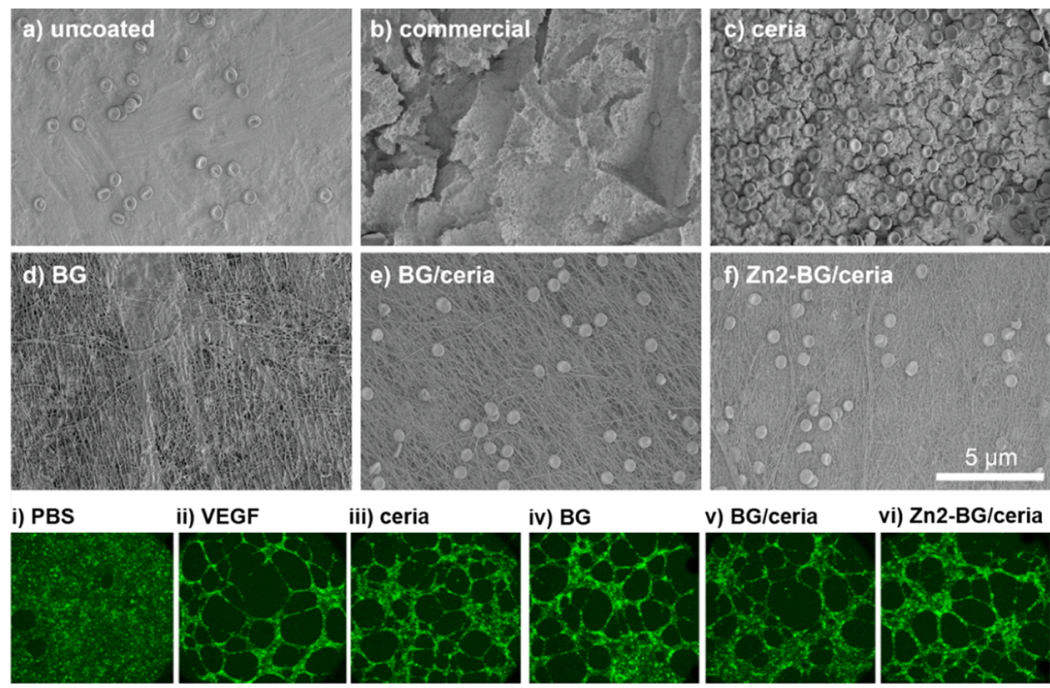

iii) ceria
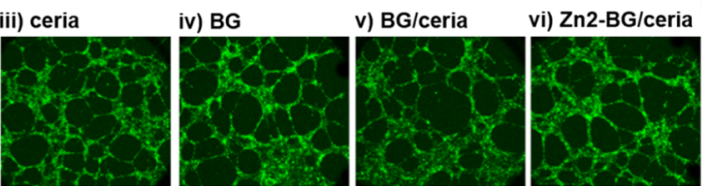

Figure 5. $(a-f)$ Blood coagulation on the implant surfaces. The implants were incubated for 20 min in human whole blood and evaluated by SEM. The (a) uncoated, (b) commercial, and (c) ceria surfaces show no to limited fibrin network formation, whereas (d-f) BG-containing coatings yield a thick fibrin network (representative images from $n \geq 3$ biological replicates). (i-vi) Angiogenic potential of the nanoparticle building blocks assessed in a tube formation assay. Representative images shown for $t=6 \mathrm{~h}$ (compare Figure S4), $n>3$.

To quantify the mechanical stability of the coatings, their asprepared mass was first quantified by weighing the disks before and after the LF-FSP process. The mass deposited on the titanium implants for each coating is reported in Table S2. Washing and sonication did not majorly affect any of the BGbased coatings but almost completely removed the pure ceria coating (72\% mass loss, compare Table S2), which is well in line with the patchiness of the ceria coating seen in the SEM image (Figure 1). Subsequently, the disks were abraded for 10 sets of 10 cycles based on the ASTM F1978 abrasion resistance norm for implant coatings. As shown in Figure 3, the BG coating is stable, which is in line with previous findings ${ }^{22}$ for porous HA coatings. While the $\mathrm{Zn} 2-\mathrm{SrBG} /$ ceria coating stability is comparable to that of $\mathrm{BG}$, the hybrid coatings are slightly less stable, which is likely due to the lower mechanical stability of the ceria coatings and the more segregated nature of the ceria and BG phases compared to the $\mathrm{Zn2}-\mathrm{SrBG} /$ ceria coating, as illustrated in Figure 1. However, all BG-containing coatings show similarly low or lower abrasion rates in comparison to $\mathrm{Ti}$ coatings in the literature (see Table S2 and Figure S3). ${ }^{47-49}$

Furthermore, the coatings were characterized by powder Xray diffraction (XRD, Figure 4a). All samples show a strong Ti background, as visible in the pattern of uncoated surfaces. The only other contributions to the patterns are attributable to ceria (Figure $4 a$ ). The potential contribution of BG is only visible as a shoulder at small angles, indicating that most of the BG has stayed amorphous and that the temperatures that the coatings experienced during the synthesis were not higher than $850^{\circ} \mathrm{C},{ }^{50}$ in line with the temperatures previously reported for similar settings and coating durations. ${ }^{51}$ At elevated temperatures, crystalline phases, including sodium calcium silicate and wollastonite, would form. ${ }^{52}$ The ceria crystallite sizes extracted from the XRD patterns based on the Scherrer method (see Table S1) are in excellent agreement with the ceria nanoparticle sizes observed by STEM (Figure 1). Crystallite sizes of $10-12 \mathrm{~nm}$ exhibit an intermediate $\mathrm{Ce}(\mathrm{III}) / \mathrm{Ce}(\mathrm{IV})$ ratio (Figure S1) optimal for the anticipated unification of antioxidant/tissue regenerative (governed by $\mathrm{Ce}(\mathrm{III})$ ) and antimicrobial (mediated by Ce(IV)) activities. ${ }^{27}$
$B G$ is known for its bone regenerative properties due to its biomineralization to HA in physiological media. ${ }^{54}$ In a dental implantation scenario, such accelerated bone formation is desired for the implant portion that connects with the jaw. Conversely, biomineralization and bone formation are unwanted for the parts of the implant that come into contact with the gingiva. To assess the biomineralization behavior of the developed coatings, nanoparticles of different compositions were immersed in SBF for 4 weeks and FTIR and Raman measurements were performed before and after (Figure 4b,c). As a reference for biomineralization, $\mathrm{HA}$ nanopowder was measured. After contact with SBF, BG and BG/ceria show an emerging FTIR band at around $1030 \mathrm{~cm}^{-1}$ and a Raman peak at $960 \mathrm{~cm}^{-1}$, both of which are characteristic for the formation of $\mathrm{PO}_{4}{ }^{3-}$ ions. ${ }^{55}$ These emerging peaks are in line with the $\mathrm{HA}$ reference and indicate the biomineralization of the $\mathrm{BG}$ phase, making BG and BG/ceria suitable coatings for the portion of the implant that comes into contact with the jaw bone. The unimpeded mineralization of $\mathrm{BG} /$ ceria is probably attributable to the segregated nature of BG/ceria. ${ }^{27}$ In contrast, $\mathrm{Zn} 2-\mathrm{SrBG} /$ ceria does not develop such bands after 4 weeks of immersion and does not seem to crystallize to $\mathrm{HA}$, which make such a coating more suitable for soft tissue contact. The mixing of the BG phase with ceria, a known inhibitor of BG mineralization, ${ }^{56}$ and the partial substitution of $\mathrm{Ca}$ with Sr greatly attenuate the mineralization behavior.

To conclude, the roughness, porosity, superhydrophilicity, and mechanical stability of the BG-based nanocoatings make them promising candidates for improved implant healing. Notably, the two hybrid coatings show distinctly different levels of biomineralization, making the $\mathrm{Zn2}$-SrBG/ceria coating more suitable for soft tissue contact. Upon insertion of an implant into the body, blood proteins such as fibrinogen and thrombin adhere to the surface and mediate platelet adhesion, ultimately leading to coagulation and thrombus formation. ${ }^{57}$ For the subsequent adhesion and differentiation of cells, a stable fibrin network on the implant surface is highly beneficial. ${ }^{58,59}$ After the initial immune response to an implant, which is mostly mediated by neutrophils, monocytes and macrophages, a variety of cells relevant to the creation of a 
a)
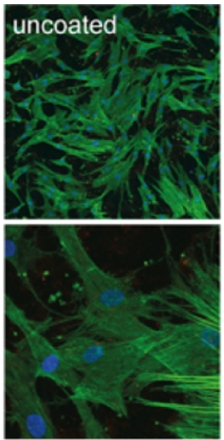

b)
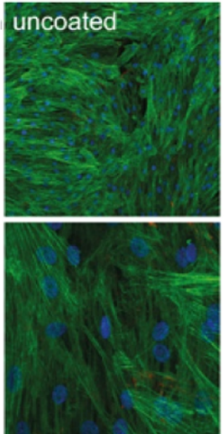
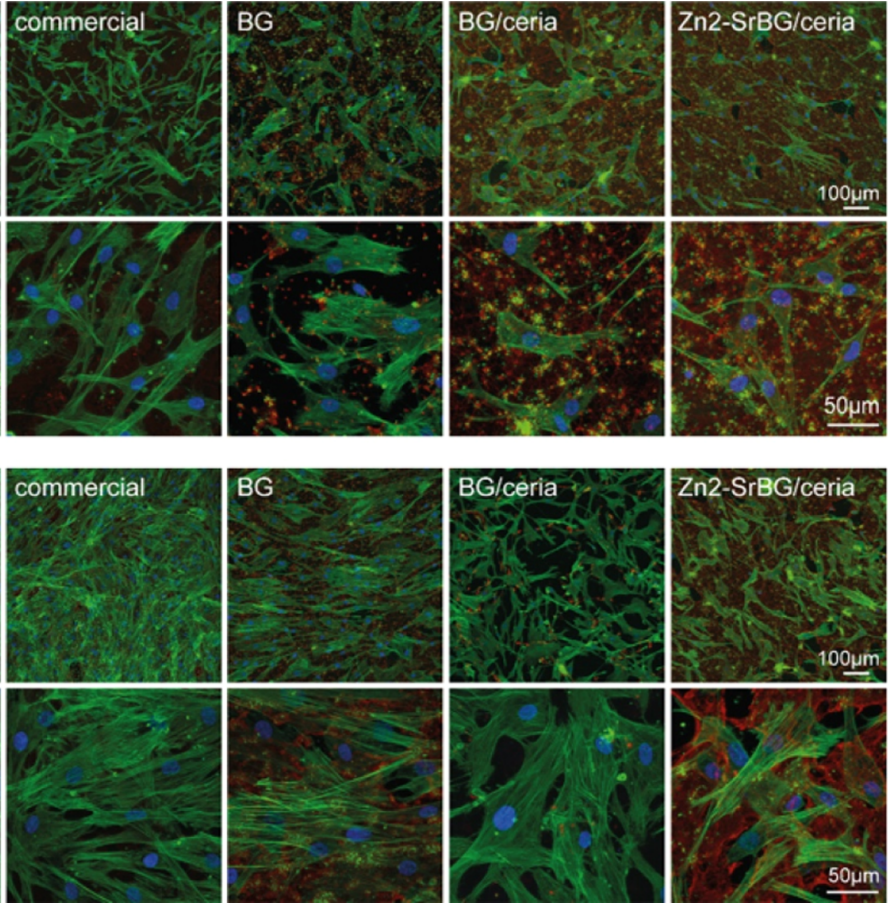

Figure 6. Human bone progenitor cell attachment and growth on the implant surfaces. Implants were incubated with human whole blood and HBCs (actin in green and nuclei in blue) were seeded on top of the formed fibrin network (red). Representative images shown at $24 \mathrm{~h}$ (a) and $96 \mathrm{~h}$ (b) $(n=3$, biological replicates).
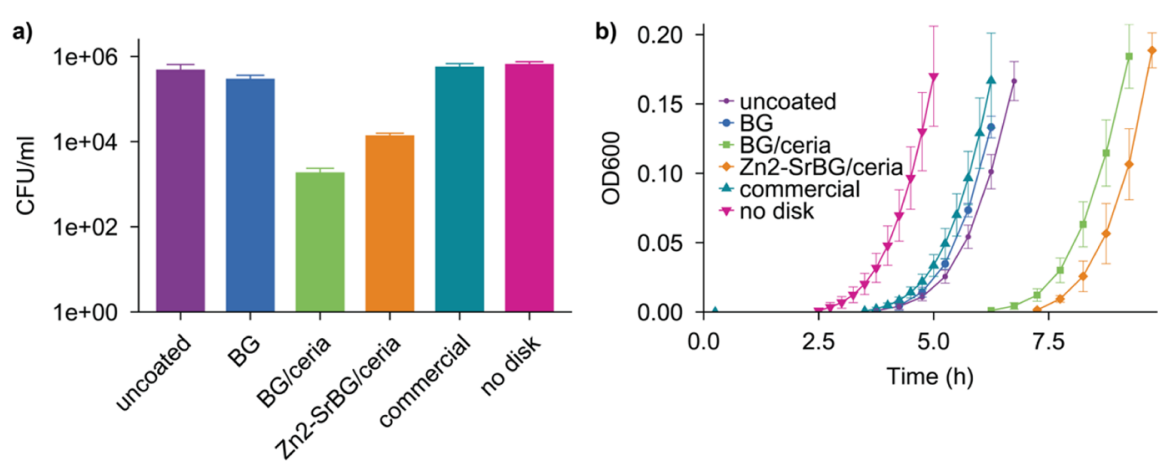

Figure 7. Bacterial growth on different implant surfaces. MRSA cultures were incubated on top of the disks and then left to grow further in the absence of the disks. (a) Colony-forming units/mL obtained by colony counting, logarithmic scale. (b) Optical density curves: cultures that have been in contact with the ceria-containing disks contain fewer bacteria and thus reach the logarithmic growth phase, hours later (in the absence of the implant disks). $n=3$ (biological repeats), mean \pm SD shown.

structural framework, try to infiltrate the implant interface. The most relevant cells in a dental implantation scenario are osteoblasts that mediate hard tissue integration, gingival fibroblasts that govern soft tissue integration, and endothelial cells that induce the formation of new blood vessels (angiogenesis). Usually, angiogenesis and osteogenesis occur in parallel and lead to osseointegration within $8-12$ weeks. ${ }^{60}$

To mimic the physiological situation during implantation, blood coagulation on the disks was evaluated as described by Kopf et al. ${ }^{61}$ and compared to a commercially available dental implant surface. The bare disks ("uncoated" and "commercial") show almost no blood coagulation, while the ceria coating shows only few blood cells on the surface (Figure 5). In contrast, a pronounced fibrin network is formed on all BGcontaining coatings, providing a temporary matrix for subsequent cell attachment.

To assess angiogenesis, the building blocks of the coating were evaluated in an endothelial tube formation model
(Figures 5 and S4). All nanoparticles, especially Zn2-SrBG/ ceria, show strong induction of tube formation, similar to the positive control VEGF. The proangiogenic activities of such formulations confirm the in vivo findings where the improved perfusion of a skin perforator flap has been demonstrated. ${ }^{29}$ Transcriptomic analysis of the endothelial cells suggests that the angiogenic effect is mediated through the regulation of hypoxia and cell differentiation pathways (Figure S5), although further mechanistic investigations are needed to pinpoint the exact process. Furthermore, none of the coating building blocks exhibits cytotoxicity toward human fibroblasts (Figure S6). Ceria nanoparticles even seem to have a cytoprotective effect which has been reported before. ${ }^{27}$ In a fibroblast woundhealing assay, especially BG-containing particles promote swift gap closure (Figure S7), which indicates strong soft tissue regenerative properties. Taken together, the nanocoating building blocks are well tolerated and stimulate the growth 
of human endothelial cells and fibroblasts, which is crucial to the soft tissue healing of the implant.

In a next step, the hard tissue integration of the nanocoatings was investigated by seeding primary human bone progenitor cells (HBCs) on coated disks that were preincubated with human whole blood (ceria coatings were excluded in the following due to poor stability). Figure 6 illustrates good cell attachment and spreading of $\mathrm{HBCs}$ on BG, $\mathrm{BG} /$ ceria, and $\mathrm{Zn} 2-\mathrm{SrBG} /$ ceria surfaces at both timepoints (24 and $96 \mathrm{~h}$ ). While at $24 \mathrm{~h}$, the attachment and spreading are comparable to that of noncoated and commercial implant surfaces, at $96 \mathrm{~h}$, a more pronounced fibrin network along with slightly lower mammalian cell densities is observed. This might be attributed to the higher bioactivities of the BG coatings, which incorporate additional features, such as angiogenic or antimicrobial properties.

Bacterial infection, one of the most common causes of implant failure, is a consequence of poor cell/tissue attachment to the surface of conventional implants. Infections around an implant are difficult to treat and typically require its removal for the anti-infectious treatment of the tissue. ${ }^{62}$ For this reason, the ideal implant coating prevents the attachment and growth of bacteria. In particular, staphylococcal strains cause severe infections $^{63}$ and can feature hard-to-treat antibiotic resistance. For these reasons, the different implant surfaces were investigated for their ability to prevent the growth of methicillin-resistant Staphylococcus aureus (MRSA) using an established protocol. ${ }^{64}$ As Figures 7 and S8 show, MRSA experiences no growth inhibition on the uncoated samples and commercially available surfaces compared to free growth ("no disk").

The BG coating inhibits growth slightly, whereas the two hybrids reduce bacterial growth by multiple orders of magnitude. The antibacterial effects may be due to surface roughness, metal ion release, or contact killing. The surface roughness appears to play a negligible role, as indicated by the minor antimicrobial effect of the pure BG coating (with comparable roughness). Similarly, the comparison to the $\mathrm{Zn}$ free $\mathrm{BG} /$ ceria coating shows that $\mathrm{Zn}$-ion release plays a minor role. Consequently, the antimicrobial effect appears to be dominated by ceria via a contact-based mechanism ${ }^{65}$ (compare Figure S9). The ion dissolution products did not show significant growth inhibition, and the released amount of cerium and zinc ions is orders of magnitude below their active concentration (Figure S10), further confirming that the antibacterial activity is primarily based on contact. Nanostructured surfaces, especially the ones containing nanoceria, may thus offer an attractive alternative to silver-based coatings or coatings containing organic antibiotic payloads. In contrast to the fascinating approaches reported by others, including the (near-infrared) light eradication of bacterial biofilms on $\mathrm{MoS}_{2},{ }^{66}$ red phosphorus, ${ }^{67}$ or polydopamine $/ \mathrm{Ag}_{3} \mathrm{PO}_{4} /$ graphene oxide coatings, ${ }^{68}$ or the integration of probiotics ${ }^{69}$ or silver ${ }^{70}$ antimicrobials, the presented nanoceria-based coatings do not rely on light activation, biologicals, or silver ion release and hence provide a robust yet nontoxic alternative.

Taken together, we demonstrate a one-step process to coat implants with bioactive coatings based on nanohybrid building blocks that can be tailored to the soft and hard tissue interface while featuring antimicrobial properties. These functional coatings can be produced in a single-step liquid-feed flame pyrolysis process. More specifically, we present two hybrid coatings (BG/ceria and $\mathrm{Zn} 2-\mathrm{SrBG} /$ ceria) which are highly porous, superhydrophilic, and stable. Both hybrid coatings induce the formation of a pronounced fibrin network upon contact with blood, which is favorable for cell attachment. These coatings unify excellent mammalian cell attachment and inhibition of antibiotic-resistant bacteria. While the $\mathrm{BG} /$ ceria coating biomineralizes and shows good attachment of bone cells, its Sr-substituted and $\mathrm{Zn}$-doped version $\mathrm{Zn} 2-\mathrm{SrBG} /$ ceria does not biomineralize and exhibits favorable soft tissue healing properties. These two coatings fulfill the major requirements of successful implant surfaces and demonstrate how hard/soft tissue integration can be promoted by directly tuning the coating composition (with comparable topologies). The parameter space accessible by LF-FSP and the deposition of hybrid building blocks exhibiting complex compositions and architectures pave the way for even more sophisticated coatings with even better bioresponse.

\section{CONCLUSIONS AND OUTLOOK}

This work demonstrates that nano-architected multicomponent metal oxide coatings obtainable via a one-step manufacturing process are superhydrophilic and offer tailorable bioactivity. These features can decrease the chance of complications compared to uncoated (commercial) Ti implant surfaces. The versatility and modularity of LF-FSP are harnessed to deposit multicomponent metal oxides that have well-defined stoichiometry, composition, and architecture in a single step. This control allows the tailoring of the coatings to both soft and hard tissue implant integration and healing. The ultrahigh porosity and wettability, the enhanced blood coagulation and good cell attachment, and their potent antimicrobial activity render the BG-ceria hybrid coatings particularly promising for applications interfacing both soft and hard tissue, hence offering a new route to address one of the biggest remaining challenges in the field. Such nanohybrid coatings offer new possibilities for coating designs with applications beyond dental implantology.

The composition of the proposed coating can be further optimized and extended by many bioactive metal oxides to which FSP gives access. The high control over the properties of nanostructures and the coating characteristics (i.e., thickness as a function of deposition time, particle sintering, and compactness as a function of temperature and material) in a one-step process opens remarkable opportunities. This approach can not only be extended to different implant geometries but also to different substrates which is of high interest to the field because dental implantation is moving toward metal-free implants, such as zirconia. $^{71}$ In vivo investigations on the coating bioactivity and stability are a logical next step to ultimately be able to comprehensively assess the therapeutic benefit of these novel coatings in conditions with full system complexity.

\section{MATERIALS AND METHODS}

NP Synthesis. All nanoparticles, except Aerosil 200, were produced by LF-FSP, as described by Matter et al. ${ }^{27}$ Aerosil 200 fumed silica particles (Sigma-Aldrich) are commercially available. Four flame-made nanoparticles were used as free particles and to coat $\mathrm{Ti}-6 \mathrm{Al}-4 \mathrm{~V}$ disks (medical grade, circular, $1 \mathrm{~mm}$ thickness, $15 \mathrm{~mm}$ diameter, Sollberger AG, Wetzikon, Switzerland). FSP was performed as follows: $5 \mathrm{~mL} / \mathrm{min}$ of the precursor solution was pumped to a water-cooled spray nozzle and dispersed by $5 \mathrm{~L} / \mathrm{min}_{2}$. The pressure drop at the nozzle tip was approx 1.5 bar. The dispersed precursor was ignited by premixed $\mathrm{CH}_{4} / \mathrm{O}_{2}(1.5: 3.2 \mathrm{~L} / \mathrm{min})$ flamelets. Particles were collected on a glass fiber filter mounted $70 \mathrm{~cm}$ above the flame 
or on Ti disks mounted $6 \mathrm{~cm}$ above the flame for $25 \mathrm{~s}$, in analogy to the procedure described by Nasiri et $\mathrm{al}^{22}$ for the coating of $\mathrm{Ti}$ with $\mathrm{HA}$. The precursor compositions were as follows: (1) ceria: $0.3 \mathrm{M}$, $100 \mathrm{wt} \%$ cerium(III) 2-ethylhexanoate in THF; (2) BG: $0.3 \mathrm{M}, 40 \mathrm{wt}$ $\%$ calcium acetylacetonate hydrate, $37 \mathrm{wt} \%$ sodium 2-ethylhexanoate, 6 wt \% tributyl phosphate, and 17 wt \% hexamethyldisiloxane (HMDSO) in THF; (3) BG/ceria: $0.3 \mathrm{M}, 68$ wt \% cerium(III) nitrate, $11 \mathrm{wt} \%$ calcium acetylacetonate hydrate, $13 \mathrm{wt} \%$ sodium 2 ethylhexanoate, 2 wt \% tributyl phosphate, and 6 wt \% HMDSO in THF; (4) Zn2-SrBG/ceria: $0.3 \mathrm{M}, 68$ wt \% cerium(III) nitrate, 5 wt $\%$ calcium acetylacetonate hydrate, 13 wt \% sodium 2-ethylhexanoate, $2 \mathrm{wt} \%$ tributyl phosphate, $6 \mathrm{wt} \%$ HMDSO in THF, $4 \mathrm{wt} \%$ strontium acetylacetonate hydrate, and $2 \mathrm{wt} \%$ zinc acetylacetonate.

As-Prepared Coating Characterization. SEM (Hitachi S-4800, Japan) coupled with energy-dispersive X-ray (EDX) spectroscopy was performed. Additionally, scanning transmission electron microscopy (STEM) on nanoparticles scraped off the disks was performed on a JEOL 2200FS TEM/STEM microscope equipped with an EDX detector for elemental analysis and operated at $200 \mathrm{kV}$.

FIB-SEM (FEI Helios 660 G3) was performed in order to determine the coating thickness. Surface roughness was measured by AFM (Nanosurf ATS 204, Switzerland) in dynamic mode. The cantilever used was Dyn190Al, with frequency $190 \mathrm{kHz}$ and force constant $48 \mathrm{~N} / \mathrm{m}$ (Nanosurf, Switzerland). Image analysis was done using Gwyddion. Wettability was measured using a goniometer Drop Shape Analyzer (Krüss, Germany). For contact angle mesurements, 2 $\mu \mathrm{L}$ of sessile water was dropped on the surfaces, and a picture was captured and the WCA was determined.

Nanoparticle Suspensions. Free nanoparticles were prepared as suspensions in $0.9 \%$ sodium chloride solution and tip sonication for 2 min on ice.

Biotransformation. XRD patterns, Fourier-transform infrared (FTIR) spectra, and Raman spectra were recorded before and after the immersion of the coated Ti disks or free nanoparticles in SBF for 1 week. SBF was prepared according to Kokubo's method, ${ }^{72}$ with the following reagents: $8.035[\mathrm{~g} / \mathrm{L}] \mathrm{NaCl}, 0.355[\mathrm{~g} / \mathrm{L}] \mathrm{NaHCO}_{3}, 0.225$ $[\mathrm{g} / \mathrm{L}] \mathrm{KCl}, 0.231[\mathrm{~g} / \mathrm{L}] \mathrm{K}_{2} \mathrm{HPO}_{4} \cdot 3 \mathrm{H}_{2} \mathrm{O}, 0.311[\mathrm{~g} / \mathrm{L}] \mathrm{MgCl}_{2} \cdot 6 \mathrm{H}_{2} \mathrm{O}$, $0.386[\mathrm{~g} / \mathrm{L}] \mathrm{CaCl}_{2} \cdot 2 \mathrm{H}_{2} \mathrm{O}, 0.072[\mathrm{~g} / \mathrm{L}] \mathrm{Na}_{2} \mathrm{SO}_{4}, 6.118[\mathrm{~g} / \mathrm{L}]$ trishydroxymethyl aminomethane, and 0.038 [mol] $\mathrm{HCl}$ XRD patterns were obtained with a Bruker D8 ADVANCE diffractometer $(40 \mathrm{kV}$, $40 \mathrm{~mA}$, and $\mathrm{CuK} \alpha$ radiation) at $2 \theta=10-90^{\circ}$. Grain size and phase composition analyses were performed by Rietveld refinement using Profex. ${ }^{73} \mathrm{CeO} 2, \mathrm{Ti} 6 \mathrm{O}$, and Ti-hcp structure files were used to fit and analyze the recorded patterns. A Varian 640-IR spectrometer was used to collect the FTIR spectra of the samples in absorbance mode (32 scans at $8 \mathrm{~cm}^{-1}$ per spectrum). Raman measurements were performed as described elsewhere. ${ }^{74}$ Measurements were performed on a WITec alpha 300R confocal Raman microscope, equipped with a UHTS 300 Vis spectrometer and an Andor Newton EMCCD camera. A linearly polarized $532 \mathrm{~nm}$ laser was used for excitation. The spectra were acquired with an integration time of $2 \mathrm{~s}$ and in at least five different locations. As a reference, commercially available HA nanopowder (Sigma-Aldrich, 693863-5G) was measured by FTIR and Raman analyses.

Abrasion Testing. A Taber abraser (Abrader, model 5135, Taber Industries, New York) with two abrading wheels (H-18 Calibrate, Taber Industries, New York) was used at $60 \mathrm{rpm}$. Every 10 cycles, the samples were washed in a sonication bath for $5 \mathrm{~min}$ in a $0.1 \%$ sodium chloride solution. This process was repeated until 100 cycles were reached.

Cell Culture. HUV-EC-C, a human umbilical endothelial cell line (ATCC), was cultured using endothelial cell growth medium 2 with $2 \%$ of the supplement mix (PromoCell). Normal human dermal fibroblasts (NHDFs, PromoCell) were cultured using Dulbecco's modified Eagle's medium, high glucose (Gibco) supplemented with $10 \%$ fetal calf serum (FCS) (Lonza), and $1 \%$ PSN $(5 \mathrm{mg} / \mathrm{mL}$ penicillin, $5 \mathrm{mg} / \mathrm{mL}$ streptomycin, and $10 \mathrm{mg} / \mathrm{mL}$ neomycin, Sigma). The primary HBCs were obtained as described previously ${ }^{61}$ and cultured in proliferation medium consisting of $\alpha$-MEM (Gibco) supplemented with 10\% FCS (Lonza), 1\% PS (Sigma), and $1 \mathrm{ng} / \mathrm{mL}$ basic fibroblast growth factor (FGF-2, Sigma). All cells were cultured at $37{ }^{\circ} \mathrm{C}$ and $5 \% \mathrm{CO}_{2}$. Commercial implant surfaces (SLA) were kindly provided by Institut Straumann AG.

Blood Preincubation of Coated Titanium Disks and Seeding of HBCs. Coated titanium disks were preconditioned for $2 \mathrm{~h}$ in sterile water and afterward incubated with human whole blood in a polytetrafluoroethylene mold, as described by Kopf et al. ${ }^{61}$ After blood incubation, the samples were rinsed three times with prewarmed phosphate-buffered saline (PBS, Sigma) before seeding $36,000 \mathrm{HBCs}$ on the disks $\left(1.8 \mathrm{~cm}^{2}\right)$ and subsequent incubation for 24 and $96 \mathrm{~h}$. The samples were prepared for further analyses as described in the following sections.

Confocal Laser Scanning Microscopy. Cells were fixed with a fixation solution containing $4 \%$ paraformaldehyde, $65 \mathrm{mM}$ PIPES, 25 $\mathrm{mM}$ HEPES, $10 \mathrm{mM}$ EGTA, and $3 \mathrm{mM} \mathrm{MgCl}_{2}$ (samples with blood) for $20 \mathrm{~min}$. After fixation, the cells were permeabilized using a $0.1 \%$ Triton X solution for $10 \mathrm{~min}$. The samples were incubated with $5 \%$ goat serum, 1\% FCS in PBS for $30 \mathrm{~min}$ at room temperature to block unspecific antibody binding and then incubated with the primary monoclonal antifibrinogen antibody (1:500, mouse IgG1 isotype, F9902, Sigma) for $1 \mathrm{~h}$ at room temperature. The samples were washed three times with PBS and incubated with a secondary antimouse antibody labeled with Alexa 555 (1:300, A21422, Molecular probe) for $1 \mathrm{~h}$ at room temperature. Finally, the samples were washed thrice with PBS and then stained with Alexa Fluor 488phalloidin (1:200, Thermo Fischer) and DAPI (1:1000, Thermo Fischer) for $1 \mathrm{~h}$ at room temperature. All antibodies were dissolved in $1 \%$ FCS in PBS (Sigma). The samples were stored in PBS (Sigma) at $4{ }^{\circ} \mathrm{C}$ before imaging with a confocal laser scanning microscope (Zeiss, LSM 780, Switzerland).

SEM of Biological Samples. Blood coagulation and cell morphology were investigated by SEM (Hitachi, S-4800). Briefly, cells were fixed in a Karnovsky solution (4\% paraformaldehyde and $2.5 \%$ glutaraldehyde) for $1 \mathrm{~h}$. The samples were then dehydrated in an ascending ethanol series, incubated with hexamethyldisilazane (HMDS, Sigma) for $30 \mathrm{~min}$, and dried overnight at room temperature. Finally, the samples were sputtered with $10 \mathrm{~nm}$ of gold-platinum (high-vacuum-coated Leica EM ACE 600) before imaging at $2 \mathrm{kV}$ acceleration voltage and $10 \mu \mathrm{A}$ current.

Tube Formation Assay. Before the experiment, the plate, pipettes, and Matrigel matrix (Corning) were brought to $4{ }^{\circ} \mathrm{C}$ overnight. $10 \mu \mathrm{L}$ of Matrigel matrix (Corning) was added at the bottom of a 96-well $\mu$-Plate Angiogenesis kit (Ibidi). Before cell seeding, the cells were resuspended in a prewarmed serum-free medium containing $1.5 \mu \mathrm{M}$ of Cell Tracker Green CMFDA dye (Thermo Fischer) for $30 \mathrm{~min}$ at $37^{\circ} \mathrm{C}$. After incubation, the cells were centrifuged at $200 \mathrm{~g}$ for $5 \mathrm{~min}$ and resuspended in prewarmed ECGM medium; 10,000 HUV-EC-C cells were seeded per well. The tube formation was followed using confocal laser scanning microscopy (CLSM) under $\mathrm{CO}_{2}$ and temperature control, $37{ }^{\circ} \mathrm{C}$ and $5 \% \mathrm{CO}_{2}$. The assay was repeated at least six times with $N>5$ per experimental condition. After $16 \mathrm{~h}$, RNA was isolated using the RNeasy Micro Kit (Qiagen). The RNA concentration and purity were measured using Nanodrop. Subsequently, next-generation sequencing was performed at the Functional Genomic Center Zurich (FGCZ; Zurich, Switzerland).

Scratch Assay. NHDFs were seeded in a 24-well plate $(50,000$ cells/well). A scratch was made using a $10 \mu \mathrm{L}$ pipette tip with a Teflon lid. After the scratch, the cells were stained with a serum-free medium containing $1.5 \mu \mathrm{M}$ of Cell Tracker CMFDA dye for $30 \mathrm{~min}$ at $37{ }^{\circ} \mathrm{C}$. The cells were washed with PBS (Sigma), and a fresh medium was added. A nanoparticle suspension was added with an end concentration of $0.05 \mathrm{mg} / \mathrm{mL}$. Cell proliferation was assessed by CLSM. The assay was repeated at least three times with $N>5$ per experimental condition.

Antimicrobial Activity. MRSA DMSZ 11729 was grown overnight in nutrient broth medium tryptic soy broth (TSB100) at $37^{\circ} \mathrm{C}, 160 \mathrm{rpm}$. Bacteria were then transferred onto a TSB agar plate to form colonies overnight at $37^{\circ} \mathrm{C}$. For each experiment, one colony was inoculated in $30 \%$ nutrient broth medium tryptic soy broth 
supplemented with $0.25 \%$ glucose (TSB30Glc) and grown overnight. Then, the bacteria were diluted to an optical density at $600 \mathrm{~nm}$ (OD600) of 0.1 and grown for $1.5 \mathrm{~h}$ to reassure that the bacteria were in the log phase. The bacterial culture was subsequently diluted to OD600 $=0.05$ in PBS, and $150 \mu \mathrm{L}$ was added on top of each implant in a 24-well plate and into empty wells as control. After incubation for $60 \mathrm{~min}$ at $37^{\circ} \mathrm{C}$, the medium was removed and the samples were gently washed twice with $1 \mathrm{~mL}$ of PBS. The samples were then added to $2.5 \mathrm{~mL}$ of PBS, bath-sonicated for $5 \mathrm{~min}$, and vortexed for $15 \mathrm{~s}$. For each sample, a serial dilution was made $\left(100,10^{-1}, 10^{-2}\right.$, and $\left.10^{-3}\right)$ in PBS and spotted in triplicates $(20 \mu \mathrm{L}$ each $)$ onto a PC agar plate. Additionally, $20 \mu \mathrm{L}$ of each dilution was added to $180 \mu \mathrm{L}$ of TSB30Glc in a 96-well plate and sealed with a gas-permeable membrane Breathe-Easy (Z380059, Sigma Aldrich). Optical density curves at $600 \mathrm{~nm}$ were recorded for $24 \mathrm{~h}$ while shaking. The PC agar plates were incubated at $37{ }^{\circ} \mathrm{C}$ until the colonies were countable. Colony-forming units were quantified using SCAN 300 with SCAN software.

Data Analysis. Data were analyzed using RStudio, Microsoft Excel, ImageJ, Gwyddion, Profex, and MountainsLab.

\section{ASSOCIATED CONTENT}

\section{(5) Supporting Information}

The Supporting Information is available free of charge at https://pubs.acs.org/doi/10.1021/acsami.1c10121.

Control over size and the cerium oxidation state by varying the process parameters; EDX point spectra; abrasion measurements according to ASTM F1978; endothelial tube formation data; transcriptomic analysis; nanoparticle building block cytotoxicity; wound healing assay data; antimicrobial activity; antimicrobial mechanism of action; ion release data; roughness data; and coating mass, thickness, and porosity (PDF)

\section{AUTHOR INFORMATION}

\section{Corresponding Author}

Inge K. Herrmann - Laboratory for Particles Biology Interactions, Swiss Federal Laboratories for Materials Science and Technology (Empa), CH-9014 St. Gallen, Switzerland; Nanoparticle Systems Engineering Laboratory, Institute of Energy and Process Engineering, Department of Mechanical and Process Engineering, ETH Zurich, CH-8092 Zurich, Switzerland; (1) orcid.org/0000-0002-3018-6796; Phone: +41 (0)58 765 7153; Email: inge.herrmann@ empa.ch, ingeh@ethz.ch

\section{Authors}

Martin T. Matter - Laboratory for Particles Biology Interactions, Swiss Federal Laboratories for Materials Science and Technology (Empa), CH-9014 St. Gallen, Switzerland; Nanoparticle Systems Engineering Laboratory, Institute of Energy and Process Engineering, Department of Mechanical and Process Engineering, ETH Zurich, CH-8092 Zurich, Switzerland

Leonida Maliqi - Laboratory for Particles Biology Interactions, Swiss Federal Laboratories for Materials Science and Technology (Empa), CH-9014 St. Gallen, Switzerland

Kerda Keevend - Laboratory for Particles Biology Interactions, Swiss Federal Laboratories for Materials Science and Technology (Empa), CH-9014 St. Gallen, Switzerland; Nanoparticle Systems Engineering Laboratory, Institute of Energy and Process Engineering, Department of Mechanical and Process Engineering, ETH Zurich, CH-8092 Zurich, Switzerland
Stefanie Guimond - Biointerfaces Laboratory, Swiss Federal Laboratories for Materials Science and Technology (Empa), CH-9014 St. Gallen, Switzerland

Judith Ng - Laboratory for Particles Biology Interactions and Biointerfaces Laboratory, Swiss Federal Laboratories for Materials Science and Technology (Empa), CH-9014 St. Gallen, Switzerland; Nanoparticle Systems Engineering Laboratory, Institute of Energy and Process Engineering, Department of Mechanical and Process Engineering, ETH Zurich, CH-8092 Zurich, Switzerland

Efe Armagan - Laboratory for Biomimetic Membranes and Textiles, Swiss Federal Laboratories for Materials Science and Technology (Empa), CH-9014 St. Gallen, Switzerland

Markus Rottmar - Biointerfaces Laboratory, Swiss Federal Laboratories for Materials Science and Technology (Empa), CH-9014 St. Gallen, Switzerland; (1) orcid.org/0000-00017636-428X

Complete contact information is available at: https://pubs.acs.org/10.1021/acsami.1c10121

\section{Author Contributions}

M.T.M. and I.K.H. conceived the study. M.T.M. coated the implants and performed characterization and bacteria experiments. L.M. was involved in the study design and performed SEM measurements, abrasion measurements, the scratch assay, the tube formation assay, and prepared samples for transcriptomic analysis and for cell culture experiments. K.K. performed FIB/SEM analyses. S.G. and J.N. performed cell experiments. E.A. analyzed the samples with AFM with the help of L.M. M.R. supervised the cell studies. I.K.H. supervised the project. M.T.M., L.M., and I.K.H. wrote the manuscript together with all coauthors. All coauthors contributed to the discussions and approved the final version of the manuscript.

\section{Notes}

The authors declare the following competing financial interest(s): M.T.M and I.K.H declare a conflict of interest in the form of inventorship on a patent application (EP19216118) related to the coating of implants with ceria/ bioglass, all other authors declare no competing interests.

\section{ACKNOWLEDGMENTS}

The authors thank Dr Enrico Bertero for the collection of optical profilometry data, Dr Alexander Gogos for the acquisition of scanning transmission electron micrographs with EDX maps, Yvonne Elbs-Glatz for cell and microscopy works, and Dr Qun Ren for access to the microbiology laboratory. The Particle Technology Laboratory of ETH Zurich is acknowledged for providing access to the reactors. The microscopy center of ETH Zurich (ScopeM) and the Empa Transport at Nanoscale Interfaces Laboratory are acknowledged for providing access to their microscopes. Transcriptomic analyses were performed at the Functional Genome Center Zurich (FGCZ). The authors acknowledge Institut Straumann AG for providing commercial implant surfaces (SLA). M.R. and I.K.H. kindly acknowledge financial support from the ITI Foundation, Switzerland. I.K.H. was supported by a Swiss National Science Foundation SNSF Eccellenza grant (no. 181290). Scheme 1 was created using BioRender.com. 


\section{REFERENCES}

(1) Legeros, R. Z.; Craig, R. G. Strategies to Affect Bone Remodeling: Osteointegration. J. Bone Miner. Res. 2009, 8, S583S596.

(2) Özcan, M.; Hämmerle, C. Titanium as a Reconstruction and Implant Material in Dentistry: Advantages and Pitfalls. Materials 2012, 5, 1528-1545.

(3) Kim, K. T.; Eo, M. Y.; Nguyen, T. T. H.; Kim, S. M. General Review of Titanium Toxicity. Int. J. Implant. Dent. 2019, 5, 10.

(4) Sicilia, A.; Cuesta, S.; Coma, G.; Arregui, I.; Guisasola, C.; Ruiz, E.; Maestro, A. Titanium Allergy in Dental Implant Patients: A Clinical Study on 1500 Consecutive Patients. Clin. Oral Implants Res. 2008, 19, 823-835.

(5) Sinha, N.; Kulshreshtha, N. M.; Dixit, M.; Jadhav, I.; Shrivastava, D.; Bisen, P. S. Nanodentistry: Novel Approaches. Nanostructures for Oral Medicine; Elsevier, 2017; pp 751-776.

(6) Baghaban-Eslaminejad, M.; Oryan, A.; Kamali, A.; Moshiri, A. The Role of Nanomedicine, Nanotechnology, and Nanostructures on Oral Bone Healing, Modeling, and Remodeling. Nanostructures for Oral Medicine; Elsevier, 2017; pp 777-832.

(7) Wagner, V.; Dullaart, A.; Bock, A.-K.; Zweck, A. The Emerging Nanomedicine Landscape. Nat. Biotechnol. 2006, 24, 1211-1217.

(8) Soares, S.; Sousa, J.; Pais, A.; Vitorino, C. Nanomedicine: Principles, Properties, and Regulatory Issues. Front. Chem. 2018, 6, 360.

(9) Kendall, M.; Lynch, I. Long-Term Monitoring for Nanomedicine Implants and Drugs. Nat. Nanotechnol. 2016, 11, 206-210.

(10) Rasouli, R.; Barhoum, A.; Uludag, H. A Review of Nanostructured Surfaces and Materials for Dental Implants: Surface Coating, Patterning and Functionalization for Improved Performance. Biomater. Sci. 2018, 6, 1312-1338.

(11) Le Guéhennec, L.; Soueidan, A.; Layrolle, P.; Amouriq, Y. Surface Treatments of Titanium Dental Implants for Rapid Osseointegration. Dent. Mater. 2007, 23, 844-854.

(12) Pachauri, P.; Bathala, L. R.; Sangur, R. Techniques for Dental Implant Nanosurface Modifications. J. Adv. Prosthodont. 2014, 6, 498. (13) Zafar, M. S.; Khurshid, Z.; Najeeb, S.; Zohaib, S.; Rehman, I. U. Therapeutic Applications of Nanotechnology in Dentistry. Nanostructures for Oral Medicine; Elsevier, 2017; pp 833-862.

(14) Parnia, F.; Yazdani, J.; Javaherzadeh, V.; Maleki Dizaj, S. Overview of Nanoparticle Coating of Dental Implants for Enhanced Osseointegration and Antimicrobial Purposes. J. Pharm. Pharm. Sci. 2017, 20, 148.

(15) von Wilmowsky, C.; Moest, T.; Nkenke, E.; Stelzle, F.; Schlegel, K. A. Implants in Bone: Part I. A Current Overview about Tissue Response, Surface Modifications and Future Perspectives. Oral Maxillofac. Surg. 2014, 18, 243-257.

(16) Smeets, R.; Stadlinger, B.; Schwarz, F.; Beck-Broichsitter, B.; Jung, O.; Precht, C.; Kloss, F.; Gröbe, A.; Heiland, M.; Ebker, T. Impact of Dental Implant Surface Modifications on Osseointegration. BioMed Res. Int. 2016, 2016, 6285620.

(17) Kopf, B. S.; Ruch, S.; Berner, S.; Spencer, N. D.; ManiuraWeber, K. The role of nanostructures and hydrophilicity in osseointegration:In-vitroprotein-adsorption and blood-interaction studies. J. Biomed. Mater. Res., Part A 2015, 103, 2661-2672.

(18) Rottmar, M.; Müller, E.; Guimond-Lischer, S.; Stephan, M.; Berner, S.; Maniura-Weber, K. Assessing the Osteogenic Potential of Zirconia and Titanium Surfaces with an Advanced in Vitro Model. Dent. Mater. 2019, 35, 74-86.

(19) Rodriguez y Baena, R.; Rizzo, S.; Manzo, L.; Lupi, S. M. Nanofeatured Titanium Surfaces for Dental Implantology: Biological Effects, Biocompatibility, and Safety. J. Nanomater. 2017, 2017, 1-18. (20) Li, J.; Wen, J.; Li, B.; Li, W.; Qiao, W.; Shen, J.; Jin, W.; Jiang, X.; Yeung, K. W. K.; Chu, P. K. Valence State Manipulation of Cerium Oxide Nanoparticles on a Titanium Surface for Modulating Cell Fate and Bone Formation. Adv. Sci. 2018, 5, 1700678.

(21) Surmenev, R.; Vladescu, A.; Surmeneva, M.; Ivanova, A.; Braic, M.; Grubova, I.; Cotrut, C. M. Radio Frequency Magnetron Sputter Deposition as a Tool for Surface Modification of Medical Implants.
Modern Technologies for Creating the Thin-Film Systems and Coatings; Books on Demand, 2017.

(22) Nasiri, N.; Mukherjee, S.; Panneerselvan, A.; Nisbet, D. R.; Tricoli, A. Optimally Hierarchical Nanostructured Hydroxyapatite Coatings for Superior Prosthesis Biointegration. ACS Appl. Mater. Interfaces 2018, 10, 24840-24849.

(23) Brunello, G.; Elsayed, H.; Biasetto, L. Bioactive Glass and Silicate-Based Ceramic Coatings on Metallic Implants: Open Challenge or Outdated Topic? Materials 2019, 12, 2929.

(24) Wood, M. R.; Vermilyea, S. G. A Review of Selected Dental Literature on Evidence-Based Treatment Planning for Dental Implants: Report of the Committee on Research in Fixed Prosthodontics of the Academy of Fixed Prosthodontics. J. Prosthet. Dent. 2004, 92, 447-462.

(25) Gröhn, A. J.; Pratsinis, S. E.; Sánchez-Ferrer, A.; Mezzenga, R.; Wegner, K. Scale-up of Nanoparticle Synthesis by Flame Spray Pyrolysis: The High-Temperature Particle Residence Time. Ind. Eng. Chem. Res. 2014, 53, 10734-10742.

(26) Starsich, F. H. L.; Herrmann, I. K.; Pratsinis, S. E. Nanoparticles for Biomedicine: Coagulation During Synthesis and Applications. Annu. Rev. Chem. Biomol. Eng. 2019, 10, 155-174.

(27) Matter, M. T.; Furer, L. A.; Starsich, F. H. L.; Fortunato, G.; Pratsinis, S. E.; Herrmann, I. K. Engineering the Bioactivity of FlameMade Ceria and Ceria/Bioglass Hybrid Nanoparticles. ACS Appl. Mater. Interfaces 2018, 11, 2830-2839.

(28) Matter, M. T.; Starsich, F.; Galli, M.; Hilber, M.; Schlegel, A. A.; Bertazzo, S.; Pratsinis, S. E.; Herrmann, I. K. Developing a Tissue Glue by Engineering the Adhesive and Hemostatic Properties of Metal Oxide Nanoparticles. Nanoscale 2017, 9, 8418-8426.

(29) Lese, I.; Graf, D. A.; Tsai, C.; Taddeo, A.; Matter, M. T.; Constantinescu, M. A.; Herrmann, I. K.; Olariu, R. Bioactive Nanoparticle-Based Formulations Increase Survival Area of Perforator Flaps in a Rat Model. PLoS One 2018, 13, No. e0207802.

(30) Matter, M. T.; Li, J. H.; Lese, I.; Schreiner, C.; Bernard, L.; Scholder, O.; Hubeli, J.; Keevend, K.; Tsolaki, E.; Bertero, E.; Bertazzo, S.; Zboray, R.; Olariu, R.; Constantinescu, M. A.; Figi, R.; Herrmann, I. K. Multiscale Analysis of Metal Oxide Nanoparticles in Tissue: Insights into Biodistribution and Biotransformation. Adv. Sci. 2020, 7, 2000912.

(31) Popa, A.-C.; Stan, G.; Husanu, M.-A.; Mercioniu, I.; Santos, L.; Fernandes, H.; Ferreira, J. Bioglass Implant-Coating Interactions in Synthetic Physiological Fluids with Varying Degrees of Biomimicry. Int. J. Nanomed. 2017, 12, 683-707.

(32) Skallevold, H. E.; Rokaya, D.; Khurshid, Z.; Zafar, M. S. Bioactive Glass Applications in Dentistry. Int. J. Mol. Sci. 2019, 20, 5960.

(33) Anil, S.; Venkatesan, J.; Shim, M. S.; Chalisserry, E. P.; Kim, S.$\mathrm{K}$. Bone response to calcium phosphate coatings for dental implants. In Bone Response to Dental Implant Materials; Piattelli, A., Ed.; Woodhead Publishing, 2017; pp 65-88.

(34) Newman, S. D.; Lotfibakhshaiesh, N.; O’Donnell, M.; Walboomers, X. F.; Horwood, N.; Jansen, J. A.; Amis, A. A.; Cobb, J. P.; Stevens, M. M. Enhanced Osseous Implant Fixation with Strontium-Substituted Bioactive Glass Coating. Tissue Eng., Part A 2014, 20, 1850-1857.

(35) Saghiri, M. A.; Asatourian, A.; Orangi, J.; Sorenson, C. M.; Sheibani, N. Functional Role of Inorganic Trace Elements in Angiogenesis-Part II: Cr, $\mathrm{Si}, \mathrm{Zn}, \mathrm{Cu}$, and S. Crit. Rev. Oncol. Hematol. 2015, 96, 143-155.

(36) Mihai, M. M.; Dima, M. B.; Dima, B.; Holban, A. M. Nanomaterials for Wound Healing and Infection Control. Materials 2019, 12, 2176.

(37) Wang, Q.; Huang, Y.; Qian, Z. Nanostructured Surface Modification to Bone Implants for Bone Regeneration. J. Biomed. Nanotechnol. 2018, 14, 628-648.

(38) Maycas, M.; Esbrit, P.; Gortázar, A. R. Molecular Mechanisms in Bone Mechanotransduction. Histol. Histopathol. 2017, 32, 751760 . 
(39) Gittens, R. A.; McLachlan, T.; Olivares-Navarrete, R.; Cai, Y.; Berner, S.; Tannenbaum, R.; Schwartz, Z.; Sandhage, K. H.; Boyan, B. D. The Effects of Combined Micron-/Submicron-Scale Surface Roughness and Nanoscale Features on Cell Proliferation and Differentiation. Biomaterials 2011, 32, 3395-3403.

(40) Jimbo, R.; Albrektsson, T. Long-term Clinical Success of Minimally and Moderately Rough Oral Implants. Implant Dent. 2015, $24,62-69$.

(41) Gittens, R. A.; Scheideler, L.; Rupp, F.; Hyzy, S. L.; GeisGerstorfer, J.; Schwartz, Z.; Boyan, B. D. A Review on the Wettability of Dental Implant Surfaces II: Biological and Clinical Aspects. Acta Biomater. 2014, 10, 2907-2918.

(42) Kota, A. K.; Kwon, G.; Tuteja, A. The Design and Applications of Superomniphobic Surfaces. NPG Asia Mater. 2014, 6, No. e109.

(43) Narayan, K.; Subramaniam, S. Focused Ion Beams in Biology. Nat. Methods 2015, 12, 1021-1031.

(44) Moore, B.; Asadi, E.; Lewis, G. Deposition Methods for Microstructured and Nanostructured Coatings on Metallic Bone Implants: A Review. Adv. Mater. Sci. Eng. 2017, 2017, 1-9.

(45) Mediaswanti, K.; Wen, C.; Ivanova, E. P.; Berndt, C. C.; Wang, J. Sputtered Hydroxyapatite Nanocoatings on Novel Titanium Alloys for Biomedical Applications. Titanium Alloys-Advances in Properties Control; Books on Demand, 2013.

(46) Gurrappa, I.; Binder, L. Electrodeposition of nanostructured coatings and their characterization-A review. Sci. Technol. Adv. Mater. 2008, 9, 043001.

(47) Lekka, M.; Zanella, C.; Klorikowska, A.; Bonora, P. L. Scalingup of the Electrodeposition Process of Nano-Composite Coating for Corrosion and Wear Protection. Electrochim. Acta 2010, 55, 78767883.

(48) Singh, A.; Singh, G.; Chawla, V. Influence of Post Coating Heat Treatment on Microstructural, Mechanical and Electrochemical Corrosion Behaviour of Vacuum Plasma Sprayed Reinforced Hydroxyapatite Coatings. J. Mech. Behav. Biomed. Mater. 2018, 85, $20-36$.

(49) Singh, A.; Singh, G.; Chawla, V. Mechanical Properties of Vacuum Plasma Sprayed Reinforced Hydroxyapatite Coatings on Ti6Al-4V Alloy. J. Australas. Ceram. Soc. 2017, 53, 795-810.

(50) Lefebvre, L.; Gremillard, L.; Chevalier, J.; Zenati, R.; BernacheAssolant, D. Sintering Behaviour of $45 \mathrm{~S} 5$ Bioactive Glass. Acta Biomater. 2008, 4, 1894-1903.

(51) Nasiri, N.; Ceramidas, A.; Mukherjee, S.; Panneerselvan, A.; Nisbet, D. R.; Tricoli, A. Ultra-Porous Nanoparticle Networks: A Biomimetic Coating Morphology for Enhanced Cellular Response and Infiltration. Sci. Rep. 2016, 6, 24305.

(52) Xin, R.; Zhang, Q.; Gao, J. Identification of the Wollastonite Phase in Sintered 45S5 Bioglass and Its Effect on in Vitro Bioactivity. J. Non-Cryst. Solids 2010, 356, 1180-1184.

(53) Kumar, S.; Srivastava, M.; Singh, J.; Layek, S.; Yashpal, M.; Materny, A.; Ojha, A. K. Controlled Synthesis and Magnetic Properties of Monodispersed Ceria Nanoparticles. AIP Adv. 2015, 5, 027109 .

(54) Hench, L. L.; Jones, J. R. Bioactive Glasses: Frontiers and Challenges. Front. Bioeng. Biotechnol. 2015, 3, 194.

(55) Timchenko, P. E.; Timchenko, E. V.; Pisareva, E. V.; Vlasov, M. Y.; Volova, L. T.; Frolov, O. O.; Kalimullina, A. R. Experimental Studies of Hydroxyapatite by Raman Spectroscopy. J. Opt. Technol. 2018, 85, 130-135.

(56) Deliormanl1, A. M. Synthesis and Characterization of Ceriumand Gallium-Containing Borate Bioactive Glass Scaffolds for Bone Tissue Engineering. J. Mater. Sci.: Mater. Med. 2015, 26, 67.

(57) Xu, L.-C.; Bauer, J. W.; Siedlecki, C. A. Proteins, Platelets, and Blood Coagulation at Biomaterial Interfaces. Colloids Surf., B 2014, 124, 49-68.

(58) Ramazanoglu, M.; Oshi, Y. Osseointegration and Bioscience of Implant Surfaces - Current Concepts at Bone-Implant Interface. Implant Dentistry - A Rapidly Evolving Practice; Books on Demand, 2011.
(59) Öncü, E.; Bayram, B.; Kantarci, A.; Gülsever, S.; Alaaddinoglu, E. Positive effect of platelet rich fibrin on osseointegration. Med. Oral Patol. Oral Cir. Bucal 2016, 21, e601-e607.

(60) Insua, A.; Monje, A.; Wang, H.-L.; Miron, R. J. Basis of Bone Metabolism around Dental Implants during Osseointegration and Peri-Implant Bone Loss. J. Biomed. Mater. Res., Part A 2017, 105, 2075-2089.

(61) Kopf, B. S.; Schipanski, A.; Rottmar, M.; Berner, S.; ManiuraWeber, K. Enhanced Differentiation of Human Osteoblasts on $\mathrm{Ti}$ Surfaces Pre-Treated with Human Whole Blood. Acta Biomater. 2015, 19, $180-190$

(62) Sakka, S.; Baroudi, K.; Nassani, M. Z. Factors Associated with Early and Late Failure of Dental Implants. J. Invest. Clin. Dent. 2012, 3, 258-261.

(63) Arciola, C. R.; Alvi, F. I.; An, Y. H.; Campoccia, D.; Montanaro, L. Implant Infection and Infection Resistant Materials: A Mini Review. Int. J. Artif. Organs 2005, 28, 1119-1125.

(64) Wu, S.; Zuber, F.; Brugger, J.; Maniura-Weber, K.; Ren, Q. Antibacterial Au Nanostructured Surfaces. Nanoscale 2016, 8, 26202625.

(65) Matter, M. T.; Doppegieter, M.; Gogos, A.; Keevend, K.; Ren, Q.; Herrmann, I. K. Inorganic Nanohybrids Combat AntibioticResistant Bacteria Hiding within Human Macrophages. Nanoscale 2021, 13, 8224 .

(66) Li, M.; Li, L.; Su, K.; Liu, X.; Zhang, T.; Liang, Y.; Jing, D.; Yang, X.; Zheng, D.; Cui, Z.; Li, Z.; Zhu, S.; Yeung, K. W. K.; Zheng, Y.; Wang, X.; Wu, S. Highly Effective and Noninvasive Near-Infrared Eradication of a Staphylococcus aureus Biofilm on Implants by a Photoresponsive Coating within 20 Min. Adv. Sci. 2019, 6, 1900599.

(67) Tan, L.; Li, J.; Liu, X.; Cui, Z.; Yang, X.; Zhu, S.; Li, Z.; Yuan, X.; Zheng, Y.; Yeung, K. W. K.; Pan, H.; Wang, X.; Wu, S. Rapid Biofilm Eradication on Bone Implants Using Red Phosphorus and Near-Infrared Light. Adv. Mater. 2018, 30, 1801808.

(68) Xie, X.; Mao, C.; Liu, X.; Tan, L.; Cui, Z.; Yang, X.; Zhu, S.; Li, Z.; Yuan, X.; Zheng, Y.; Yeung, K. W. K.; Chu, P. K.; Wu, S. Tuning the Bandgap of Photo-Sensitive Polydopamine/Ag3PO4/Graphene Oxide Coating for Rapid, Noninvasive Disinfection of Implants. ACS Cent. Sci. 2018, 4, 724-738.

(69) Tan, L.; Fu, J.; Feng, F.; Liu, X.; Cui, Z.; Li, B.; Han, Y.; Zheng, Y.; Yeung, K. W. K.; Li, Z.; Zhu, S.; Liang, Y.; Feng, X.; Wang, X.; Wu, $S$. Engineered Probiotics Biofilm Enhances Osseointegration via Immunoregulation and Anti-Infection. Sci. Adv. 2020, 6, No. eaba5723.

(70) Zhang, Y.; Liu, X.; Li, Z.; Zhu, S.; Yuan, X.; Cui, Z.; Yang, X.; Chu, P. K.; Wu, S. Nano Ag/ZnO-Incorporated Hydroxyapatite Composite Coatings: Highly Effective Infection Prevention and Excellent Osteointegration. ACS Appl. Mater. Interfaces 2018, 10, 1266-1277.

(71) Flamant, Q.; Caravaca, C.; Meille, S.; Gremillard, L.; Chevalier, J.; Biotteau-Deheuvels, K.; Kuntz, M.; Chandrawati, R.; Herrmann, I. K.; Spicer, C. D.; Stevens, M. M.; Anglada, M. Selective Etching of Injection Molded Zirconia-Toughened Alumina: Towards Osseointegrated and Antibacterial Ceramic Implants. Acta Biomater. 2016, 46, $308-322$.

(72) Kokubo, T.; Kushitani, H.; Sakka, S.; Kitsugi, T.; Yamamuro, T. Solutions able to reproducein vivo surface-structure changes in bioactive glass-ceramic A-W3. J. Biomed. Mater. Res. 1990, 24, 721734

(73) Doebelin, N.; Kleeberg, R. Profex: a graphical user interface for the Rietveld refinement programBGMN. J. Appl. Crystallogr. 2015, 48, $1573-1580$.

(74) Saxena, N.; Keilhofer, J.; Maurya, A. K.; Fortunato, G.; Overbeck, J.; Müller-Buschbaum, P. Facile Optimization of Thermoelectric Properties in PEDOT:PSS Thin Films through Acido-Base and Redox Dedoping Using Readily Available Salts. ACS Appl. Energy Mater. 2018, 1, 336-342. 